\title{
Karyotype analysis of mithun (Bos frontalis) and mithun bull $x$ Brahman cow hybrids
}

\author{
K.-X. Qu ${ }^{1,2,3 *}$, Z.-X. He ${ }^{2 *}$, W.-H. Nie ${ }^{4}$, J.-C. Zhang ${ }^{2}$, X.-D. Jin ${ }^{2}$, G.-R. Yang ${ }^{2}$, \\ X.-P. Yuan' ${ }^{2}$, B.-Z. Huang ${ }^{2}$, Y.-P. Zhang ${ }^{3,4}$ and L.-S. Zan ${ }^{1,5}$ \\ ${ }^{1}$ College of Animal Science and Technology, \\ Northwest A \& F University, Yangling, Shaanxi, China \\ ${ }^{2}$ Yunnan Academy of Grassland and Animal Science, Kunming, Yunnan, China \\ ${ }^{3}$ Yunnan Key Laboratory of Molecular Biology of Domestic Animal and \\ Laboratory of Molecular Evolution and Genome Diversity, \\ Kunming Institute of Zoology, Chinese Academy of Sciences, Kunming, China \\ ${ }^{4}$ State Key Laboratory of Genetic Resources and Evolution, \\ Kunming Institute of Zoology, Chinese Academy of Sciences, Kunming, China \\ ${ }^{5}$ National Beef Cattle Improvement Centre of China, Yangling, Shaanxi, China
}

*These authors contributed equally to this study.

Corresponding author: L.-S. Zan

E-mail: zanls@yahoo.com.cn.

Genet. Mol. Res. 11 (1): 131-140 (2012)

Received August 8, 2011

Accepted November 13, 2011

Published January 19, 2012

DOI http://dx.doi.org/10.4238/2012.January.19.1

\begin{abstract}
We examined the cytogenetics of mithun (Bos frontalis), a domesticated version of the Asian gaur, and hybrids $\left(\mathrm{F}_{1}\right.$ generation) produced by artificial insemination of Brahman cows (Bos indicus) with mithun semen. Reproductive potential was also examined in the $\mathrm{F}_{1}$ generation and a backcrossed heifer for utilization of heterosis. Metaphase chromosome spreads were examined by conventional staining and fluorescence in situ hybridization hybridized with the entire chromosome 1 of mithun as a specific
\end{abstract}


probe. Chromosome 1 of mithun was found to be equivalent to Bos taurus chromosomes 2 and 28. The karyotype of the female mithun $(\mathrm{N}=4)$ comprised 58 chromosomes, including 54 acrocentric and four large submetacentric chromosomes, without the four acrocentric chromosomes found in the domesticated species $B$. indicus. However, one of the four female mithuns with a normal mithun phenotype had an abnormal karyotype $(2 \mathrm{n}=59)$, indicating introgression from $B$. taurus or $B$. indicus. The $\mathrm{F}_{1}$ karyotypes $(\mathrm{N}=6,3 \pi 3+)$ of the mithun bull $\times$ Brahman cow cross had $2 \mathrm{n}=59$, intermediate between their parents; they were consistent heterozygous carriers with a centric fusion involving $\operatorname{rob}(2 ; 28)$, as expected. Two pronounced red signals were seen in the mithun karyotypes, three red signals in the mithun $\times$ Brahman hybrids, and four red signals in the Brahman cattle, in good agreement with centric fusion of bovine $\operatorname{rob}(2 ; 28)$. The female backcross hybrid $(\mathrm{N}=1)$ with $2 \mathrm{n}=59$ had a similar chromosome configuration to the $\mathrm{F}_{1}$ karyotypes and had $\operatorname{rob}(2 ; 28)$. Such female backcross hybrids normally reproduce; however, the $\mathrm{F}_{1}$ bulls $(\mathrm{N}=3)$ had not yet generated normal sperm at 24 months.

Key words: Karyotype; Mithun (Bos frontalis); Rob(2;28); Brahman cow (Bos indicus); Hybrids of mithun x Brahman

\section{INTRODUCTION}

Extant Bovidae species include domestic cattle (Bos indicus and Bos taurus), java or banteng (Bos javanicus), yak (Bos grunniens), gaur (Bos gaurus), mithun (Bos frontalis), and many kinds of hybrids among the genus Bos crossings, of which their close relationship is due to the Robertsonian translocations of bovine chromosomes. Robertsonian translocations have been documented, such as rob(15;25), $\operatorname{rob}(1 ; 29)$, rob(2;28), rob(15;25), rob(7;21), $\operatorname{rob}(4 ; 20)$, $\operatorname{rob}(16 ; 18), \operatorname{rob}(16 ; 20), \operatorname{rob}(4 ; 10)$, and so on. Of the Robertsonian translocations, $\operatorname{rob}(1 ; 29)$ and $\operatorname{rob}(2 ; 28)$ were the most common, which were considered as ancient origin with reduced fertility (subfertility) in the heterozygous carriers (Gustavsson, 1969; Blazak and Eldridge, 1977; Popescu, 1990; Rubes et al., 1999; Vadhanakul et al., 2004).

In China, mithun called "Dulong cattle" by the Dulong people, inhabit the rainforests of the Gaoligongshan Mountains and Drung River Basin, feeding on bamboo and various leaves of trees and shrubs (Figure 1A, B). The current population is less than 3000 individuals in the Yunnan Province. Thus, Dulong cattle was listed in the 130th NOTICE of the "Directory of National Livestock and Poultry Genetic Resources Protection" by the Chinese Minister of Agriculture in August 2000. Phenotypic characteristics of Dulong cattle are the same as those of Thai gaur, Indian gaur and Malayan gaur (Lekagul and McNeely, 1977, 1988; Kakampuy et al., 2007), of which coat colors are dark brown near to that of buffalo's with respect to the presence of a distinct spinous dorsal ridge but not an indicine (zebu) hump and feet with white stockings (Figure 1C, D). A bulging forehead ridge above the nose and a pair of wide and short ears distinguish them from domestic cattle (He et al., 2009a). 


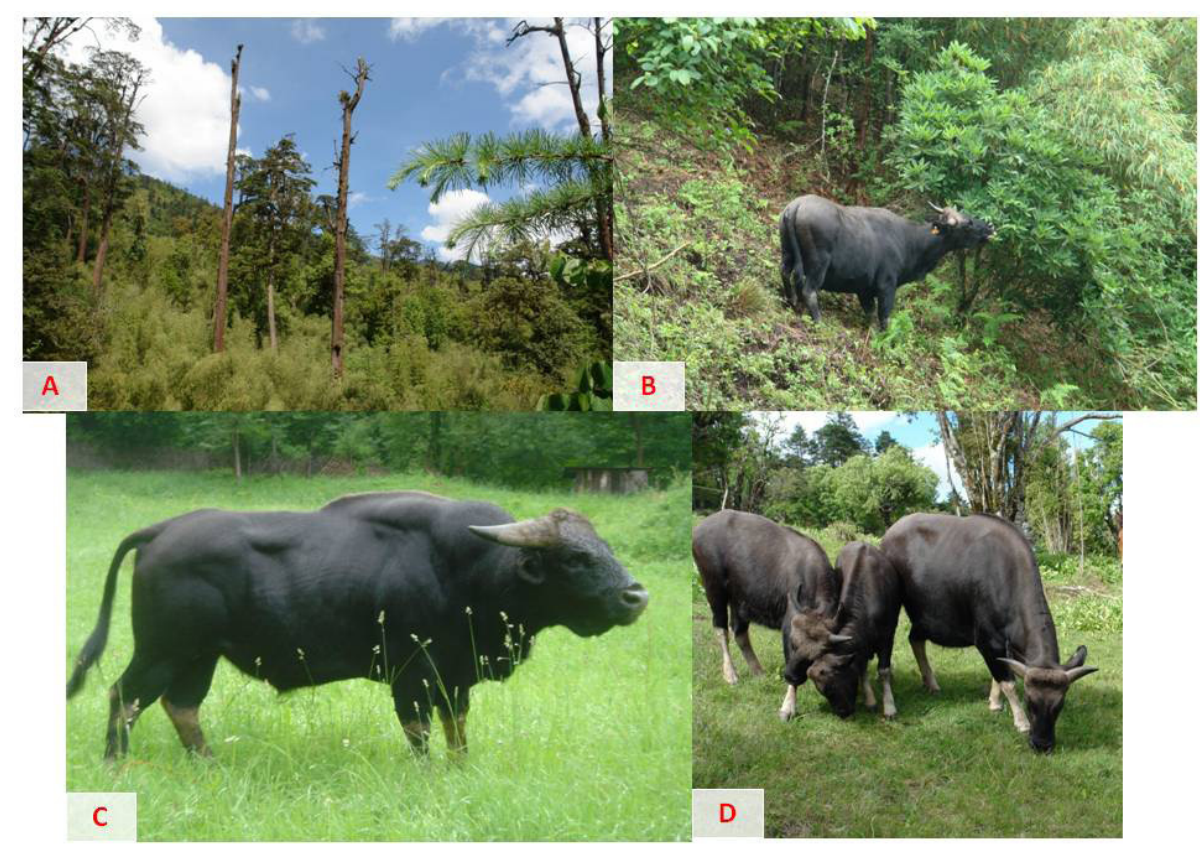

Figure 1. Residential surroundings and phenotype of mithun. A. Residential surroundings and regenerated forests. B. Eating leaves. C. Mithun bull. D. Mithun cows with white stockings.

It is well known that the normal karyotype of mithun (B. frontalis) is close to the gaur karyotype $(2 \mathrm{n}=58)$, consisting of 27 pairs of acrocentric chromosomes, one pair of submetacentric chromosome and the submetacentric sex chromosomes. An abnormal karyotype (2n $=57$ ) from a female gaur instead of normal $2 \mathrm{n}=58$ or $2 \mathrm{n}=56$ has been reported (Kakampuy et al., 2007). The aim of this study was to determine the cytogenetic chromosome rearrangements of mithun and the hybrids produced by artificial insemination (AI) through mithun semen crossed Brahman (introduced from Australia), involving centric fusion in the $\mathrm{F}_{1}$ generations. Also discussed is the reproductive potential of the $\mathrm{F}_{1}$ generation and a backcross heifer (Brahman bull $\mathrm{x} \mathrm{F}_{1}$ female) for the utilization of heterosis.

\section{MATERIAL AND METHODS}

\section{Animals}

Brahman cows grazed throughout the year on the Xiaoshao Farm of Yunnan Academy of Grassland and Animal Science, Kunming, China, which were fed on whole corn silage supplemented with $\mathrm{CaH}_{2} \mathrm{PO}_{4}$, urea and soybean or rapeseed meal during the 6 months of the winter-spring period. After natural mating and following pregnancy diagnosis, nulliparous and multiparous healthy Brahman cows were selected to be submitted to synchronous estrus and AI, which had body weights ranging from 350 to $550 \mathrm{~kg}$ at the age of 5-12 years. Estrus onset in cows was checked three times daily during the daytime after removal of the progesterone 
suppository for 12-76 $\mathrm{h}$ to confirm the optimum AI time (He et al., 2008). The desirable-onset cows were serviced twice using $0.25 \mathrm{~mL}$ frozen straw semen. About 90 days later, pregnancy diagnosis was done by hand.

\section{Medicine and reagents}

The following materials were obtained as noted: CUE-MATE ${ }^{\mathrm{TM}}$ with progesterone suppository (2nd-Generation CIDR containing 1.56 g progesterone; Duirs PfarmAg Ltd., Newsland), cloprostenol (each $0.2 \mathrm{mg}$, Shanghai Institute of Planned Parenthood Research, Shanghai), PGF $_{2 \alpha}$ (Pharmacia \& Upjohn Company, USA), FSH (Denka Pharmaceutical Co. Ltd., Japan), and DAPI staining solution and cy3-avidin (Beyotime Co. Ltd., Shanghai).

\section{Frozen straw semen}

The mithun semen straws were produced by the Yunnan Domestic Animal Frozen Semen Station, China (each frozen straw of $0.25 \mathrm{~mL}$, Lot No. 19990311), of which live sperm count was 0.60 and thaw-progressive activity was 0.34 (He XC et al., 2000; He Z et al., 2008, 2009b).

\section{Sampling}

Peripheral blood samples from the jugular vein or tail artery $(5 \mathrm{~mL})$ were collected from four female mithuns (4ㅇ), six $\mathrm{F}_{1}$ hybrids $\left(3{ }^{\top}\right.$ ) ) of mithun $\times$ Brahman cow through $\mathrm{AI}$, and one backcross hybrid (1 9 ), which was reared on the Xiaoshao Farm. The mithuns were introduced from the Phoenix Mountains and Gaoligongshan Moutains, Nujiang Prefecture; the only areas in China that mithun inhabit. The samples were kept in $10-\mathrm{mL}$ vacuum tubes containing heparin to prevent blood clotting, placed in a mixing ice-bottle to take back to the laboratory.

\section{Cell culture and preparation}

Cell culture and preparation of metaphase chromosome spreads were done according to previously reported methods (Liu et al., 1996; Zhao et al., 2007; Peng et al., 2010). The bovine chromosomes were arranged by means of the GENUS software (version 4.0) based on the chromosome size gradient and numbered from the largest to smallest.

\section{Fluorescence in situ hybridization (FISH)}

Chromosome painting with whole chromosome 1 of mithun was used as a specific probe hybridized described by Chi et al. (2005). FISH protocol was performed essentially as described by Ropiquet et al. (2008), Peng et al. (2010), and Mao et al. (2010). The probe was denaturated at $70^{\circ} \mathrm{C}$ for $10 \mathrm{~min}$, and annealing was done for $30 \mathrm{~min}$ at $37^{\circ} \mathrm{C}$. Chromosome preparations were denaturated in $70 \%$ formamide at $65-67^{\circ} \mathrm{C}$ for $1.5 \mathrm{~min}$ and quenched in $70 \%$ ice-cold ethanol (precooled in $-20^{\circ} \mathrm{C}$ freezer) for $1 \mathrm{~min}$. Slides were dehydrated in ethanol series (70, 90 and 100\%) for $2 \mathrm{~min}$ in each, and dried at room temperature. Hybridization was carried out in a humid box overnight at $37^{\circ} \mathrm{C}$. Posthybridization, the slides were washed once at $45^{\circ} \mathrm{C}$ in $2 \mathrm{X} \mathrm{SSC}$ for $2-5 \mathrm{~min}$ and $50 \%$ fomamide solution, 
and then washed twice in $2 \mathrm{X} \mathrm{SSC}$ for $5 \mathrm{~min}$ and once in $4 \mathrm{X} \mathrm{T}(200 \mathrm{~mL} 4 \mathrm{X} \mathrm{SSC}, 100 \mu \mathrm{L}$ Tween-20, mixed and subdivided into 4 staining jars). Later, $100 \mu \mathrm{L}$ cy3-avidin was placed on the chromosome preparations, and the slides were covered with plastic films and incubated at $37^{\circ} \mathrm{C}$ for $20 \mathrm{~min}$; the membranes were then removed, and the slides were washed three times in $4 \mathrm{X} \mathrm{T}$ for $5 \mathrm{~min}$ at room temperature, and quenched with DAPI. For FISH, biotin-labeled probes were visualized by cy3-avidin (final concentration $1 \mu \mathrm{g} / \mathrm{mL}$; Amersham). Slides were examined and photographed using a microscope under the GENUS software for image capture and analysis.

\section{RESULTS}

\section{Cytogenetic observation}

The karyotype of the female mithun consisted of 58 chromosomes, including 54 acrocentric and four large submetacentric chromosomes (Figure 2A, B), which were devoid of four acrocentric chromosomes compared to those of domestic B. indicus. Surprisingly, one of the four female mithuns with a normal mithun phenotype had an abnormal karyotype of $2 \mathrm{n}=$ 59 instead of the normal $2 \mathrm{n}=58$ (Figure 2C, D).
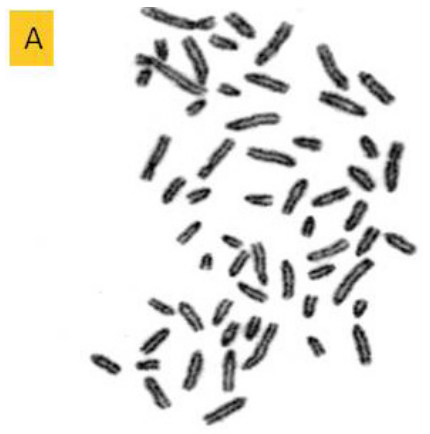

C

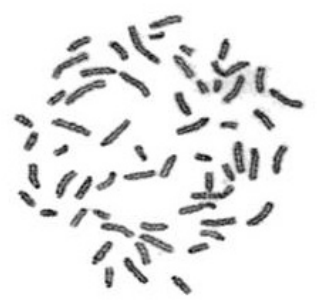

B

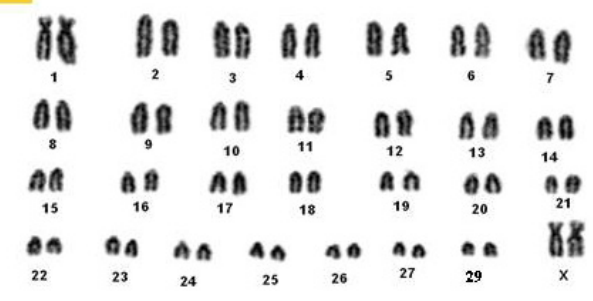

D

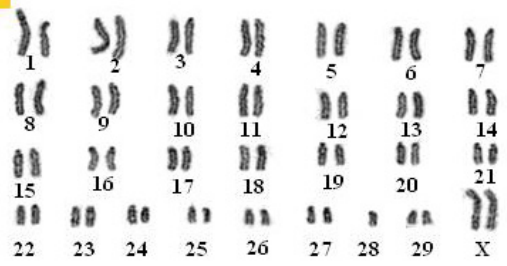

Figure 2. Karyotype of female mithun, $2 \mathrm{n}=58$ and $2 \mathrm{n}=59$. A. B. Normal karyotype of mithun, $2 \mathrm{n}=58$. C. D. Abnormal karyotype of mithun, $2 \mathrm{n}=59$.

The $\mathrm{F}_{1}$ karyotypes of mithun $\times$ Brahman cow had $2 \mathrm{n}=59$, intermediate between their parents; they were consistent heterozygous carriers with a centric fusion involving chromosomes 2 and 28, as expected (Figure 3A-F), which consisted of 57 acrocentric (Y-chromosome was the smallest acrocentric) and two large submetacentric chromosomes in the $\mathrm{F}_{1}$ bulls, while 
consisting of 56 acrocentric and three large submetacentric chromosomes in female heifers containing two submetacentric X-chromosomes.
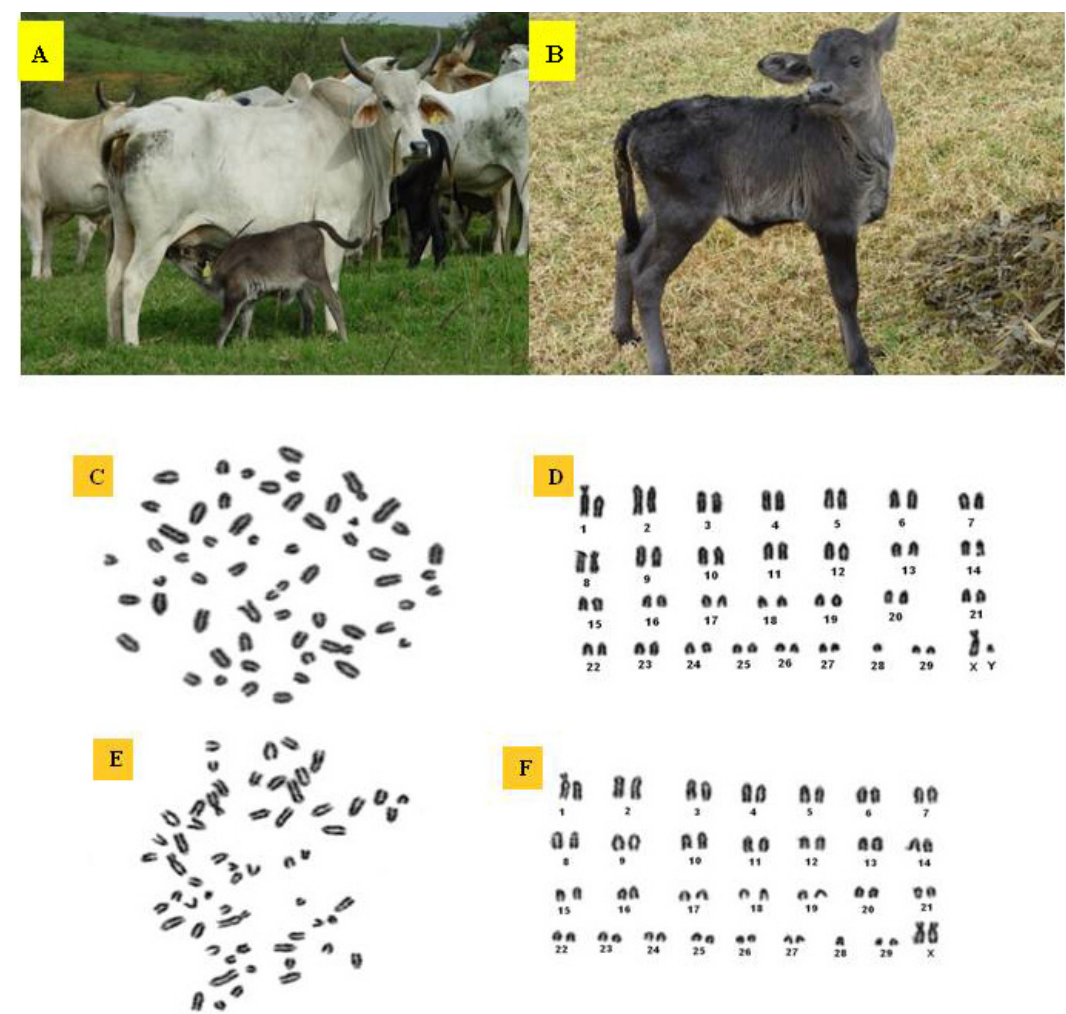

Figure 3. $F_{1}$ hybrid of mithun $x$ Brahman cow, and karyotypes of the $F_{1}$ generation. A. B. Brahman cow and the $F_{1}$ calf of mithun $x$ Brahman cow. C. D. Karyotype of the $F_{1}$ bull. E. F. Karyotype of the $F_{1}$ heifer.

\section{FISH analysis}

FISH analysis using the whole chromosome 1 of mithun as a specific probe was performed to indicate the karyotype arrangements of mithun and their hybrids of mithun $\times$ Brahman. The whole chromosome 1 of mithun (B. frontalis) in this study was equivalent to $B$. taurus chromosomes 2 and 28 (Chi et al., 2005). Two pronounced red signals were seen in the karyotypes of mithun, and three red signals in the hybrids of mithun $\mathrm{x}$ Brahman, while four red signals in Brahman cattle (Figure 4A-D), in good agreement with the centric fusion of bovine $\operatorname{rob}(2 ; 28)$ (Gallagher Jr. and Womack, 1992; Chi et al., 2005; Ropiquet et al., 2008), and exclusive $\operatorname{rob}(1 ; 29)$ due to very low incidence of $\operatorname{rob}(1 ; 29)$ in Brahman cattle (De Luca et al., 2002).

\section{Karyotype of female backcross hybrid}

The female backcross hybrid with $2 \mathrm{n}=59$ had a similar chromosome configuration as $\mathrm{F}_{1}$ karyotypes and underwent rob(2;28) based on conventional staining and FISH analysis (Figure 5A-D). 

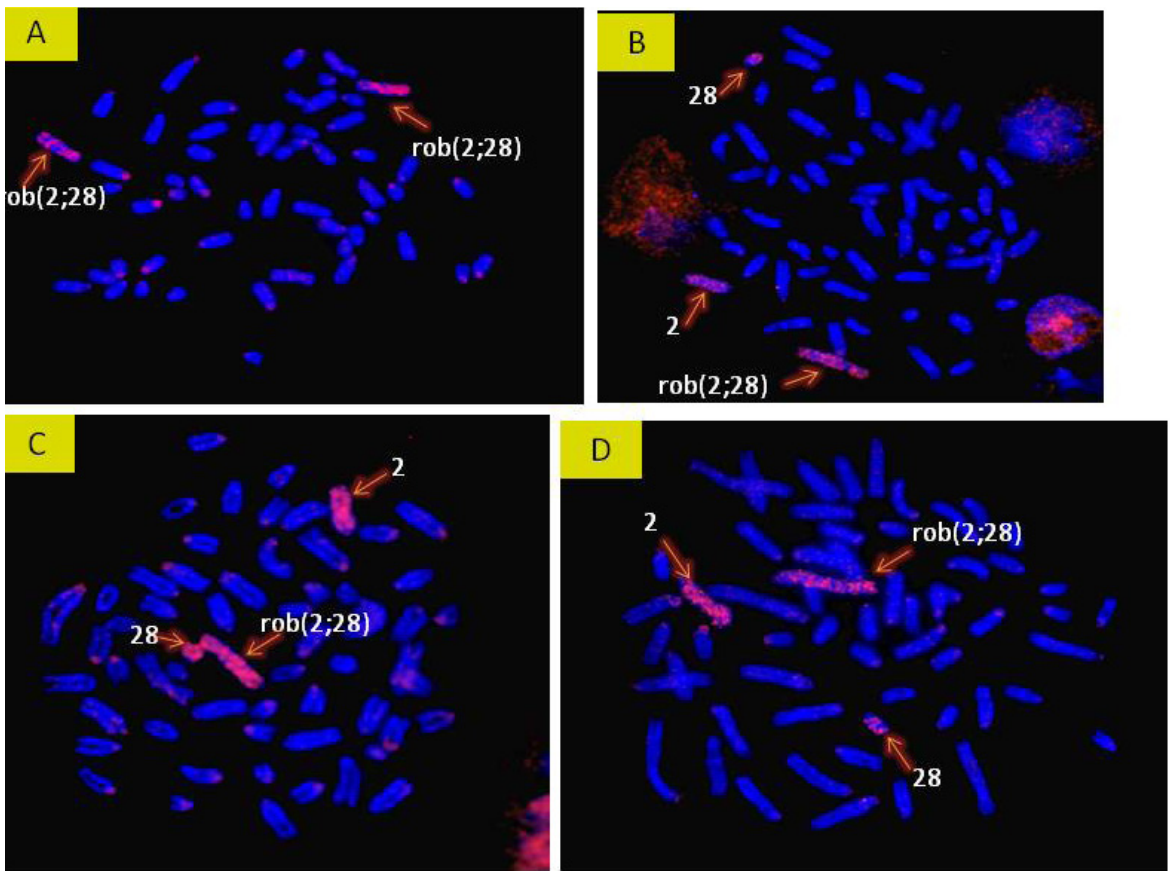

Figure 4. FISH analysis of the whole chromosome 1 of mithun in metaphase. A. B. Karyotype of mithun cow with FISH painting (blue and red). C. D. FISH painting and rob(2;28) (red) hybridized by the whole chromosome 1 of mithun in metaphase of the female $\mathrm{F}_{1}$ hybrid $(2 \mathrm{n}=59)$. The chromosomes were counterstained with DAPI (blue); the following is the same.
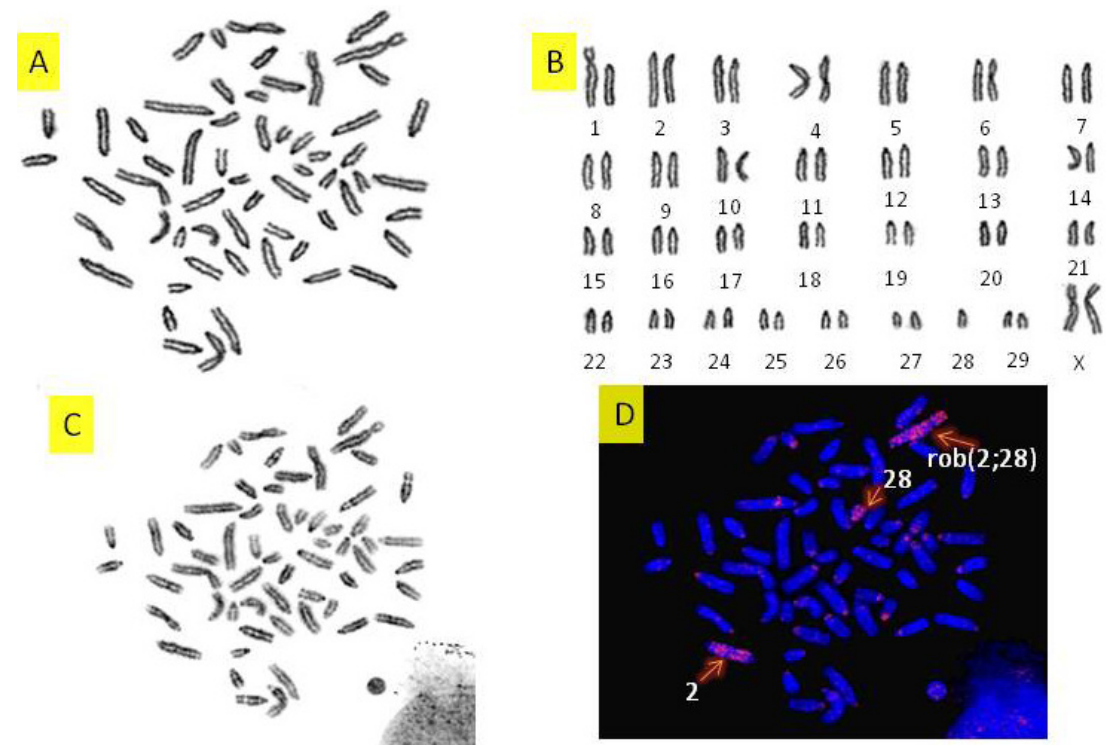

Figure 5. Karyotype of female backcross hybrid. A. B. Karyotype of female backcross with conventional staining. C. D. FISH painting of the whole chromosome 1 of mithun in metaphase of the female backcross $(2 \mathrm{n}=59)(\mathrm{red})$. 


\section{DISCUSSION}

The bovid chromosome evolution had a common primitive karyotype of 58 acrocentric autosomes and two sex chromosomes like domestic cattle, yak, domestic goat, and many other bovids (Wurster and Benirschke, 1968; Buckland and Evans, 1978). Since Gustavsson reported rob(1;29) in Swedish Red and White cattle by measuring the chromosome length (Gustavsson and Rockborn, 1964; Gustavsson et al., 1976), more than 25 centric fusions (Robertsonian translocations) have been found in more than 50 cattle breeds (Long, 1985; Popescu, 1990). Gallagher Jr. and Womack (1992) reported that the gaur and domestic cattle possessed common homologous chromosomes by Q-banding. The submetacentric autosomes of gaur (B. gaurus) were characterized as $\operatorname{rob}(1 ; 29)$ and $\operatorname{rob}(2 ; 28)$ originating from centric fusions of chromosomes 1 and 29, or 2 and 28 (Berland et al., 1988; Riggs et al., 1997; Mastromonaco et al., 2004; Kakampuy et al., 2007; Abdullah et al., 2009).

Modi et al. (1996) confirmed that bovine satellite I DNA of gaur chromosomes and the biarmed autosomes had less satellite I DNA than did the other acrocentric autosomes. Tanaka et al. (2000) surmised rob(2;28) chromosome in Vietnamese cattle by conventional and FISH staining, but it was unclear if the animal they used was a hybrid of cattle and gaur. Herein, we yielded interspecies crossbreeding calves between mithun semen and Brahman cow through AI. Both the chromosome numbers and FISH analysis supported the potential of interspecies crossing between $B$. frontalis and $B$. indicus (Winter et al., 1986, 1988). In addition, the $\mathrm{F}_{1}$ hybrids showed significant vigor with larger body and superior growth performances compared to their parents (He et al., 2008).

Recently, in Southeast Asia, the arrangements of $\operatorname{rob}(1 ; 29)$ were found in Malayan gaur (B. gaurus hubbacki) and captive Thai gaur (B. gaurus readei) (Kakampuy et al., 2007; Abdullah et al., 2009), while the arrangement of $\operatorname{rob}(2 ; 28)$ was found in Vietnamese yellow cattle $(B$. taurus) (Tanaka et al., 2000). Then, the arrangement $\operatorname{rob}(2 ; 28)$ was confirmed to happen in the interspecies crossing between mithun (B. frontalis) cross Brahman cow (B. indicus) based on the karyotypes and FISH by using the specific probe of whole chromosome 1 of mithun.

The habitation, distribution, edibility, and phenotype of mithun (B. frontalis) are similar to the gaur (B. gaurus). The karyotypes of mithun showed two rearrangement patterns, $2 \mathrm{n}=58$ and $2 \mathrm{n}=59$, which indicated that there had been a certain degree of introgression from $B$. taurus or B. indicus (Gou et al., 2010; Tanaka et al., 2011; Baig M, Mitra B, Qu KX, Peng MS, et al., unpublished data) due to the availability of freely grazing mithun and yellow cattle together and no reproduction isolation between mithun and yellow cattle in Southeast Asia (Payne and Hodges, 1997; He et al., 2008). Thus, it is suggested that mithun conservation be reinforced selection to exclude the hybrids of mithun $\mathrm{x}$ yellow cattle or yellow cattle $\mathrm{x}$ mithun and isolation from yellow cattle in the breeding and conservation program, and elimination of heterozygous AI bull.

Intercrossing in animal breeding is very popular, and it is possible that there was accidental mating in the history of bovid species. However, chromosomal abnormalities are usually accompanied by reduced fertility in the heterozygous carriers, lower conception rates at first service, congenital abnormalities, or early embryonic death (Blazak and Eldridge, 1977; King et al., 1981; Poppesu, 1990; Vadhanakul et al., 2004). In such case, the female $F_{1}$ normally reproduced with whatever crossed in our observation even if grazing together or by AI. However, the $\mathrm{F}_{1}$ bulls did not produce semen normally at the age of 15 and 24 months, as assessed by electroejaculation, while other cattle breeds produce normal sperm at the same ages, in full 
accord with the male hybrids of mithun $\times$ siri (B. indicus) (Winter et al., 1986, 1988). Further tracing of the fertility and spermatogenesis of the $\mathrm{F}_{1}$ sires with their growth is in progress.

\section{ACKNOWLEDGMENTS}

Research supported by the Sci-Tech Tackle Key Project and High-Tech Development Program of the Yunnan Province (\#2006NG23), the General Program of Applied Basic Research of the Yunnan Province (\#2006C0068M), the Sci-Tech Tackle Key Project of the Yunnan Province (\#2008LA018), the National "863" Program of China (\#2008AA101010), the Special Plan of Public Sector of Ministry of Agriculture, China (\#NYHYZX07-035), and the Technological Innovation and Training Innovative Talents Program of the Yunnan Province (\#2010CI082).

\section{REFERENCES}

Abdullah MH, Idris I and Hilmi H (2009). Karyotype of Malayan gaur (Bos gaurus hubbackl), Sahiwal-Friesian cattle and gaur x cattle hybrid backcrosses. Pak. J. Biol. Sci. 12: 896-901.

Berland HM, Sharma A, Cribiu EP, Darre R, et al. (1988). A new case of Robertsonian translocation in cattle. J. Hered. 79: 33-36.

Blazak WF and Eldridge FE (1977). A Robertsonian translocation and its effect upon fertility in Brown Swiss cattle. $J$. Dairy Sci. 60: 1133-1142.

Buckland RA and Evans HJ (1978). Cytogenetic aspects of phylogeny in the Bovidae. I. G-banding. Cytogenet. Cell Genet. 21: 42-63.

Chi J, Fu B, Nie W, Wang J, et al. (2005). New insights into the karyotypic relationships of Chinese muntjac (Muntiacus reevesi), forest musk deer (Moschus berezovskii) and gayal (Bos frontalis). Cytogenet. Genome Res. 108: 310-316.

De Luca JC, Zufriategui L, Picco SJ, Ripoli MV, et al. (2002). Incidence of 1/29 translocation in Bolivian Creole and Brahman Yacumeno cattle. Theriogenology 58: 1273-1281.

Gallagher DS Jr and Womack JE (1992). Chromosome conservation in the Bovidae. J. Hered. 83: 287-298.

Gou X, Wang Y, Yang S, Deng W, et al. (2010). Genetic diversity and origin of Gayal and cattle in Yunnan revealed by mtDNA control region and SRY gene sequence variation. J. Anim. Breed. Genet. 127: 154-160.

Gustavsson I (1969). Cytogenetics, distribution and phenotypic effects of a translocation in Swedish cattle. Hereditas 63: 68-169.

Gustavsson I and Rockborn G (1964). Chromosome abnormality in three cases of lymphatic leukaemia in cattle. Nature 203: 990.

Gustavsson I, Hageltorn M and Zech L (1976). Identification of the 1/29-translocation in the Swedish Red and White (SRB) cattle breed by utilization of new staining techniques. Hereditas 82: 260-262.

He XC, Shen F, Ji WZ and Zhao JC (2000). Successful electroejaculation and semen cryopreservation of Bos frontalis. Acta Theriol. Sin. 20: 232, 239-240.

He Z, Zhang J, Qu K and Huang B (2008). Application of frozen sperm of mithun in superovulation of zebu and parentage identification of crossbred $F_{1}$ (mithun x Brahman). Sci. Agr. Sin. 41: 2436-2441.

He Z, Qu K, Yuan X and San Y (2009a). Appearance characteristic and major behavior of gayal (Bos frontalis) on the conservation ex situ in Phoenix Mountains. J. Yunnan Agric. Univ. 24: 225-230.

He Z, Zhao J, Huang B and Yuan X (2009b). Effect of thawing temperature on live sperm count and morphological profile of gayal (Bos frontalis) semen under normal temperature. Southwest China J. Agric. Sci. 22: 1093-1098.

Kakampuy W, Tanomtong A, Chaveerach A and Sangpakdee W (2007). New Robertsonian translocation chromosomes in captive Thai gaur (Bos gaurus readei). Pak. J. Biol. Sci. 10: 2185-2191.

King WA, Linares T and Gustavsson I (1981). Cytogenetics of preimplantation embryos sired by bulls heterozygous for the 1/29 translocation. Hereditas 94: 219-224.

Lekagul B and McNeely (1977). Mammals of Thailand. 1st edn. Kurusapha Ladprao Press, Bangkok.

Lekagul B and McNeely (1988). Mammals of Thailand. 2nd edn. Sahakarn Bhaet, Bangkok.

Liu R, Nai W, Chen Y and Yu D (1996). A study on the chromosomes of white-cheeked gibbon (Hylobates leacogenys). Zool. Res. 17: 341-346. 
Long SE (1985). Centric fusion translocations in cattle: a review. Vet. Rec. 116: 516-518.

Mao XG, Wang JH, Su WT, Wang YX, et al. (2010). Karyotypic evolution in family Hipposideridae (Chiroptera, Mammalia) revealed by comparative chromosome painting, G- and C-banding. Dongwuxиe Үanjiu 31: 453-460.

Mastromonaco GF, Coppola G, Crawshaw G, DiBerardino D, et al. (2004). Identification of the homologue of the bovine $\operatorname{Rob}(1 ; 29)$ in a captive gaur (Bos gaurus). Chromosome Res. 12: 725-731.

Modi WS, Gallagher DS and Womack JE (1996). Evolutionary histories of highly repeated DNA families among the Artiodactyla (Mammalia). J. Mol. Evol. 42: 337-349.

Payne WJA and Hodges J (1997). Origin of Cattle and Possible Centers of Domestication. In: Tropical Cattle: Origins, Breeds, and Breeding Policies (Payne WJA and Hodges J, eds.). Blackwell Science Ltd., Osney Mead, 3-32.

Peng KJ, Wang JH, Su WT, Wang XC, et al. (2010). Characterization of two human lung adenocarcinoma cell lines by reciprocal chromosome painting. Dongwuxue Yanjiu 31: 113-121.

Popescu CP (1990). Chromosomes of the Cow and Bull. In: Domestic Animal Cytogenetics (McFeely RL, ed.). Academic Press, San Diego, 41-71.

Riggs PK, Owens KE, Rexroad CE and Amaral MEJ (1997). Development and initial characterization of a Bos taurus x B. gaurus interspecific hybrid backcross panel. J. Hered. 88: 373-379.

Ropiquet A, Gerbault-Seureau M, Deuve JL and Gilbert C (2008). Chromosome evolution in the subtribe Bovina (Mammalia, Bovidae): The karyotype of the Cambodian banteng (Bos javanicus birmanicus) suggests that Robertsonian translocations are related to interspecific hybridization. Chromosome Res. 16: 1107-1118.

Rubes J, Machatkova M, Jokesova E and Zudova D (1999). A potential relationship between the 16;20 and 14;20 Robertsonian translocations and low in vitro embryo development. Theriogenology 52: 171-180.

Tanaka K, Yamamoto Y, Amano T, Yamagata T, et al. (2000). A Robertsonian translocation, rob(2;28), found in Vietnamese cattle. Hereditas 133: 19-23.

Tanaka K, Takizawa T, Murakoshi H, Dorji T, et al. (2011). Molecular phylogeny and diversity of Myanmar and Bhutan mithun based on mtDNA sequences. Anim. Sci. J. 82: 52-56.

Vadhanakul NW, Tunwattana P, Sekkasiddhi M and Tansatit M (2004). Karyotype of crossbred progeny born to the interspecies hybridization of wild and zebu cattle with reference to their fertility and growth performance. Thai $J$. Vet. Med. 34: 73-82.

Winter H, Mayr B, Schleger W, Dworak E, et al. (1986). Genetic characterisation of the mithun (Bos frontalis) and studies of spermatogenesis, blood groups and haemoglobins of its hybrids with Bos indicus. Res. Vet. Sci. 40: 8-17.

Winter H, Kalat M, Mayr B, Dworak E, et al. (1988). Mithun cross siri hybrids: cyto- and immunogenetic examinations and characterisation of abnormal spermatogenesis. Res. Vet. Sci. 45: 86-100.

Wurster DH and Benirschke K (1968). Chromosome studies in the superfamily Bovoidea. Chromosoma 25: 152-171.

Zhao S, Pang Y, Deng W and Wang Y (2007). Analysis on the karyotype and G-banding of chromosomes in He'nan Large Tail Sheep. J. Northwest A \& F Univ. Nat. Sci. 37: 17-20. 